\title{
A Dicotomia Objetividade-Subjetividade associada à Práxis no Campo Secretarial
}

The Objectivity-Subjectivity Dichotomy associated with Secretarial Field Praxis

Katia Denise Moreira ${ }^{1}$, Luci Mari Aparecida Rodrigues ${ }^{2}$,Stefani de Souza ${ }^{3}$ e Juliana Cidrack Freire do Vale ${ }^{4}$ 1,2,3,4 Universidade Federal de Santa Catarina, UFSC 


\section{Resumo}

Neste estudo objetiva-se discutir como se estabelece a complementaridade na dicotomia objetividade-subjetividade, relacionada ao processo de construção da práxis no campo secretarial. No que se refere aos procedimentos metodológicos, trata-se de pesquisa bibliográfica e documental, de abordagem qualitativa. Quanto à natureza é básica e, também, descritiva acerca do objetivo abordado. As técnicas utilizadas para a coleta de dados foram a bibliográfica e a documental. Utilizou-se da Análise de Conteúdo para tratamento dos dados. Os resultados apontaram que, aspectos inerentes à dicotomia em questão contribuíram para a transição de postura do sujeito secretário, que antes se caracterizava por realizar ações como um agente passivo e executor de tarefas, para um perfil contemporâneo, cuja tônica é a proatividade e o posicionamento de gestor que o profissional alcançou. Desse modo, depreende-se dos dados que há uma situação de complementariedade na transição no campo de atuação secretarial da objetividade para a subjetividade.

Palavras-chave: objetividade, subjetividade, campo secretarial

\section{Abstract}

This study aim is to discuss how complementarity is established in the objectivity-subjectivity dichotomy, related to the process of building praxis in the secretarial field. Regarding methodological procedures, this is a bibliographic and documentary research, with a qualitative approach. As for the nature, it is basic and descriptive in relation to the objective. The techniques used for data collection were bibliographic and documental. Content Analysis was used for data treatment. The results pointed out that aspects inherent to the dichotomy in question contributed to the posture transition of the secretary subject, who was previously characterized by performing actions as a passive agent and tasks executor, to a contemporary profile, whose emphasis is on proactivity and the positioning of manager that the professional has reached. Thus, it appears from the database that there is a complementary transition process in the secretarial field, from objectivity to the subjectivity.

Keywords: objectivity, subjectivity, secretarial field 
Por dicotomia entende-se a divisão de um fenômeno em duas partes caracterizadas, essencialmente, pela contrariedade (Abbagnano, 2007; Japiassu, 1991). Todavia, há de se considerar a possibilidade de reflexão sobre a complementaridade entre as diferenças, visto que uma parte pode sustentar, validar, explicar ou interpretar a outra, cada uma a partir de suas próprias concepções sobre um determinado problema.

Ao exposto, acrescenta-se a dicotomia objetividade-subjetividade, a primeira associada às questões externas ao indivíduo, àquilo que é concreto e, a segunda, relacionada às observações peculiares da realidade (Costa \& Krüger, 2003). Ou seja, pondera-se sobre a complementaridade entre ambas, dado o pressuposto de que a subjetividade pode ser considerada ponto de partida da objetividade, se associada às concepções prévias do indivíduo sobre um fenômeno observado. Esse processo pode, por exemplo, ser assistido na atuação dos atores sociais enquanto praticantes capazes de intervir no contexto social, por meio de sua contribuição para o processo de construção da práxis e das práticas sociais.

Diante disso, considerado o interesse de pesquisa deste trabalho, optou-se por àqueles atores do campo secretarial, cuja atuação profissional evoluiu durante os últimos trinta anos, principalmente após a década de 1990, devido à ampliação de recursos na área tecnológica, bem como de mudanças no contexto econômico e social das nações (Moreira, Rodrigues, Vale, \& Rosa, 2016). Essa conjuntura passou a influenciar de forma incisiva o campo organizacional, o que exigiu do secretário o aprimoramento de suas competências (Moreira, 2018). Tal reflexão vai ao encontro do discutido sobre a intensificação de novas situações nas organizações, o que passou a exigir dos profissionais de secretariado a aquisição de competências diferenciadas, além das já adquiridas (Willers \& Bortolotto, 2005).

Nessa direção, sustenta-se que houve uma transição em termos de execução-gestão no que se refere à atuação secretarial nas organizações e que tal movimento pode estar associado ao posicionamento do praticante em relação à práxis e a prática, bem como à dicotomia objetividade-subjetividade que se conecta a esse processo. Considerada tal premissa, surge como questionamento deste estudo: como se estabelece a complementaridade na dicotomia objetividade-subjetividade, relacionada ao processo de construção da práxis no campo secretarial? Considerado o problema, este estudo tem por objetivo discutir como se estabelece a complementaridade na dicotomia objetividade-subjetividade, relacionada ao processo de construção da práxis no campo secretarial.

O estudo se justifica pela importância em trazer elementos teóricos de cientificidade para a área secretarial, principalmente, no que se refere a sua atuação, visto que constatações apenas técnicas não são suficientes para o desenvolvimento de um campo de conhecimento; dado que há possibilidade de se utilizar conhecimentos de outras áreas quando o propósito é alargar ou apurar a problemática, enriquecer seus instrumentos conceituais e aperfeiçoar técnicas de investigação de um determinado campo (Serva, Dias \& Alperstedt, 2010). É relevante dizer que este estudo se alinha a outros já realizados na mesma direção, como por exemplo, o de Nonato Júnior (2009), Sabino e Marchelli (2009), Maçaneiro e Kuhl (2013) e Martins, Leal, Souza e Todorov (2017). No entanto, as discussões propostas por esses pesquisadores ocorrem sem uma aproximação direta entre a atuação secretarial e a práxis, prática e praticante, o que se constitui como uma lacuna teórico-empírica a ser explorada. 


\section{Pressupostos Metateóricos}

Dentre as abordagens epistemológicas dos estudos organizacionais, Burrell e Morgan (1979) tratam da teoria social e da teoria das organizações, a partir de pressupostos metateóricos, que se encontram de maneira implícita ou explícita nos objetos de investigação dos pesquisadores. Tais pressupostos contemplam, então, a natureza do mundo social e da forma como esse é examinado, bem como podem ser considerados sob duas dimensões: quanto à natureza da ciência social (objetiva-subjetiva) e acerca da natureza da sociedade (regulaçãomudança radical) (Barbosa da Silva \& Neto, 2006; Burrel \& Morgan, 1979). A partir disso, Burrell e Morgan (1979) elaboraram um modelo que contempla quatro paradigmas - humanista radical e interpretativista, associados à subjetividade e estruturalista radical e funcionalista, à objetividade. Nesse sentido, Peci $(2006$, p. 39) explica que "embora reconhecendo a predominância do paradigma funcional, os autores [Burrel e Morgan, 1979] enfatizaram que todos os paradigmas são igualmente legítimos. No entanto, também contribuíram para cristalizar as dicotomias, entre as quais a objetividade-subjetividade, uma vez que a categorização que os autores propõem pressupõe a existência e a exclusividade mútua de seus componentes."

Trata-se, logicamente, de uma definição de "lados" ou a objetividade ou a subjetividade. Todavia, de acordo com Peci (2006), é possível a superação dessa dicotomia, inclusive com a construção de possibilidades de uma relação complementar entre elas nos estudos organizacionais, transpassando assim as fronteiras disciplinares e metodológicas. A autora explica que a controvérsia entre um e outro fenômeno é debate antigo e que muitas correntes teóricas nasceram a partir dos posicionamentos filosóficos/sociais sobre uma ou outra.

Nessa direção, Peci (2006) apresenta três posicionamentos frente à dicotomia: a) assumir posição unilateral; b) síntese entre objetividade-subjetividade e c) rejeição a dicotomia. Diante de tal cenário, este estudo direciona seus esforços para a proximidade entre o objetivo e o subjetivo, seguindo os pressupostos de estruturação de Giddens (1984) e a concepção de campus-habitus de Bourdieu (1990). Os autores, segundo Peci (2006) teorizam a partir de uma relação dialética entre a dicotomia objetividade/subjetividade e constroem referenciais sobre diversas perspectivas, quais sejam: a fenomenologia, individualismo metodológico, estruturalismo, funcionalismo, pragmatismo e marxismo.

Dessa maneira, Giddens (1984), ao discutir as práticas sociais, desconsidera o dualismo social/individual, no qual o primeiro se materializa em teorias que engessam a capacidade de mobilização do sujeito, enquanto o segundo abrange o privilégio da intencionalidade e subjetividade sobre as práticas sociais. Para Giddens (1984), é importante ser sensível às competências dos atores, para coordenar seu comportamento no cotidiano, uma vez que são eles, os sujeitos, que possuem conhecimento acerca das condições que enfrentam, as consequências dos seus atos, naquilo que se refere às suas atividades diárias. $\mathrm{O}$ autor explica, ainda, que a estrutura é o meio pelo qual a prática se reproduz.

Na tentativa de conciliar objetividade e subjetividade, para além do empirismo e o teoricismo, Bourdieu (1990) desenvolveu sua teoria em alicerces construtivistas/estruturalistas. Para Schenato (2011), o estruturalismo de Bourdieu (1990) vai na direção de que independentemente daquilo que o sujeito pensa ou deseja, existem 
estruturas objetivas que condicionam e orientam suas ações, práticas e representações. Já, o construtivismo, manifesta-se na gênese social daquilo que é percepção e ação do habitus, que também constrói os campos, os grupos e as classes sociais (Schenato, 2011).

Para Bourdieu (1996) o habitus gera práticas distintas, são como esquemas classificatórios que abrangem visões diferentes. O teórico explica que é na prática que o habitus do sujeito se atualiza. No entanto, os sujeitos “[...] ao mesmo tempo em que não são inteiramente obedientes às estruturas, também não são inteiramente livres delas, não há como alguém criar algo totalmente novo, ou fazer o que quiser sem levar em conta os condicionamentos sociais e históricos (Schenato, 2011, p. 35). Na mesma perspectiva, está à crítica de Bourdieu (2001) ao enquadramento paradigmático estabelecido por Burrell e Morgan (1979), quando o autor expressa que ao se escolher um dos lados, o indivíduo não percebe o controle ou a censura exercidos pelo próprio polo, que delimita o campo de discussões, excluindo qualquer tomada de posição já não prevista.

A esse contexto, alinha-se a práxis, sustentada pela concepção de que os problemas principais do indivíduo estão vinculados a questões práticas de sua existência (Abbagnano, 2007; Japiassu, 1991). A práxis materializa-se na natureza das atividades diárias, que envolvem tanto a rotina, quanto sua não existência; o formal, o informal e as atividades, em multiníveis, em todo o contexto organizacional que podem ser ampliadas ou mudarem ao longo do tempo (Jarzabkowski, 2005; Orlikowski, 2010; Whittington, 2006).

Observa-se que a práxis envolve outros dois elementos, a prática, ou seja, as ferramentas sociais, simbólicas e materiais por meio das quais as atividades ocorrem, que se desdobram em ações (Jarzabkowski, 2005; Whittington, 2006) e os praticantes, aqueles que realizam as atividades, a partir das práticas, por meio de processos interativos que promovem ação coletiva (Jarzabkowski, Balogun, \& Seidl, 2007; Whittington, 2006). Em complemento ao exposto, tem-se que a prática, quando fomentada pela reflexão crítica e, alicerçada pela teoria, constitui a práxis. Desse modo, emergem dois elementos dicotômicos no processo de construção da práxis - as ações ou práticas em si e, por outro, a reflexão crítica/teórica (Sabino \& Marchelli, 2009).

Nessa direção, ao retomar a reflexão na linha construtivista, Hatchuel (2005), trata do fenômeno da prática baseado na desmistificação metafísica da ação, relacionada ao resgate da natureza recursiva da ação humana, que versa sobre a inseparabilidade dos saberes do indivíduo e das suas relações com o meio em que habita e reivindica um caráter construtivo e criativo da gestão, que está ora influenciada pela teoria, ora pela prática. Vale destacar que, o construtivismo em termos de representação cognitiva, assume, a partir de Le Moigne (2007), duas hipóteses fundadoras: a) fenomenológica, baseada fundamentalmente em Jean Piaget (1896-1980) e caracterizada pela inseparabilidade entre a ação de conhecer um objeto e o do sujeito se auto conhecer; isto é, a interação cognitiva entre esse objeto e o modo de elaboração desse conhecimento pelo sujeito; e b) teleológica, na qual o ato de conhecer leva em consideração a finalidade do sujeito, uma vez que este interpreta o objeto em termos tanto de causas finais aristotélicas, quanto em termos endógenos, produzidos pelo sujeito em si mesmo.

É na concepção fenomenológica que Grisales (2011) trata a perspectiva construtivista, ou seja, o conhecimento resultaria da apreensão de uma realidade complexa, na qual o sujeito, ao mesmo tempo em que 
busca conhecê-la a constrói, a interpreta e a cria, inserindo-se em um processo, no qual recria a si mesmo. Nesse sentido, Lane (2002, p. 17) explica que "a subjetividade é construída na relação dialética entre o indivíduo e a sociedade e suas instituições, ambas utilizam as mediações das emoções, da linguagem, dos grupos, a fim de apresentar uma objetividade questionável, responsável por uma subjetividade na qual estes códigos substituem a realidade."

Na mesma corrente, Costa e Krüger (2003) dizem que a subjetividade pode ser considerada como o ponto de partida da objetividade e se associa às concepções prévias do indivíduo. Assim, a subjetividade, para os autores, está relacionada à observação, já a objetividade está alinhada a tudo aquilo que está fora do sujeito, ou seja, vincula-se "[...] às teorias científicas, uma postura de 'independência do observador', ao desenvolvimento de 'alguma coisa concreta', à reprodutibilidade, isto é, à capacidade de demonstração e confirmação independentes" (Costa \& Krüger, 2003, p. 5). Na Figura 1, apresenta-se uma comparação entre as concepções dos fenômenos objetividade e subjetividade.

\section{Figura 1}

Objetividade e Subjetividade: Comparação em termos de construção teórico-prática.

\begin{tabular}{ll}
\hline Autor & \multicolumn{1}{c}{ Objetividade } \\
\hline Japiassú \& Marcondes (2001) $\quad$ Característica daquilo que existe \\
independentemente do pensamento. \\
Em um sentido epistemológico, \\
tentativa de constituir uma ciência \\
que se afaste da sensibilidade \\
e da subjetividade, baseando \\
suas conclusões em observações \\
controladas, em verificações, medidas \\
e experimentos, cuja validade seja \\
garantida pela possibilidade de \\
reproduzi-los e testá-los.
\end{tabular}

Característica daquilo que é objetivo. Algo que existe independente da vontade do sujeito. Está associado à percepção sem distorção, por preferências, preconceitos ou vieses.
Característica do sujeito; aquilo que é pessoal, individual, que pertence ao sujeito e apenas a ele, sendo, portanto, em última análise, inacessível a outrem e incomunicável. A filosofia chama de "subjetivas" as qualidades segundas, pois não constituem propriedades dos objetos, mas "afetações" dos sujeitos que as percebem.

Enfatiza a natureza fragmentada do sentido e considera o eu como uma construção cultural ou simbólica. 


\begin{tabular}{ccc}
\hline Autor & Objetividade & Subjetividade \\
\hline Abbagnano (2007) & Caráter da consideração que procura ver & Termo moderno que designa a doutrina \\
& o objeto como ele é, não levando & que reduz a realidade ou os valores a \\
& em conta as preferências ou os & estados ou atos do sujeito (universal ou \\
& interesses de quem o considera, mas & individual). Nesse sentido, o idealismo é \\
& apenas procedimentos intersubjetivos & subjetivo porque reduz a realidade das \\
& de averiguação e aferição. Neste & coisas a estados do sujeito (percepções \\
& significado, a objetividade é um & ou representações). Caráter do que é \\
& ideal de que a pesquisa científica & subjetivo no sentido de ser aparente, \\
& se aproxima à medida que dispõe & ilusório ou falível. \\
& de técnicas convenientes. Qualquer & \\
doutrina que admita a existência & \\
de objetos (significados, conceitos, & \\
verdades, valores, normas, etc.) válidos & \\
\hline
\end{tabular}

Nota. Elaborado pelas autoras com base em Japiassú e Marcondes (2001), Bruce e Yearley (2006), Abbagnano (2007)

Supõe-se a partir do ilustrado na Figura 1, que a construção do conhecimento científico se faz alicerçado no objetivismo, visto a necessidade do rigor e da confiabilidade, entretanto, esse conhecimento ao se concretizar no empirismo, amalgama-se ao subjetivismo, visto que a prática se dá, por meio do sujeito.

Assim, entende-se que a dicotomia ora apresentada pode ser compreendida como complementar, apesar de haver, ainda, correntes tradicionais, que tendem a polarizá-la. Após a teorização desenvolvida ao longo desta seção, passa-se, ao segundo aporte teórico deste estudo, que trata da profissão secretarial em seu percurso evolutivo em termos de competências, a partir de elementos que podem demonstrar uma possível síntese do campo secretarial no que diz respeito a dicotomia objetividade/subjetividade, diante das competências do sujeito secretário.

\section{A Evolução da Atuação Secretarial}

A profissão de secretário/secretária tem evoluído ao longo dos anos, acompanhando mudanças paradigmáticas, tanto no contexto mundial quanto no brasileiro. Sobre essa postura, ressalta-se o surgimento da figura da mulher como secretária, no Século XX, quando os homens, que desempenhavam tal função, foram para os campos de batalha nas duas Grandes Guerras Mundiais (Natalense, 1995). Evidencia-se, também, o avanço tecnológico que, no final do mesmo período, ganhou força e resultou na inserção da tecnologia nos escritórios, fato que proporcionou novos processos organizacionais (Ribeiro, 2002), os quais impulsionaram a profissão, que tomou novos rumos (Neiva \& D’Elia, 2009; Nonato Junior, 2009).

Nesse sentido, destaca-se que, à época, a ponderação que se fazia era a de que a profissão sucumbiria à inovação. No entanto, a informática e o processo de downsizing foram os maiores responsáveis pela mudança no papel do secretário executivo nas organizações (Veiga, 2010). Tem-se, ainda, que ao fazer uso dessas ferramentas 
o profissional passou a ter a oportunidade de se integrar com os processos e com a gestão das organizações e, ainda, a partir da redução dos níveis hierárquicos, muitas das atividades que antes eram desempenhadas pelas médias gerências, passaram a ser executadas pelo secretário, fato que ampliou as responsabilidades e elevou o grau de complexidade das tarefas que o profissional executa (Veiga, 2010). Adelino e Silva (2012) complementam o exposto, ao mencionarem que a era tecnológica auxiliou o secretário, no sentido de ele gerir melhor o seu tempo, o que lhe proporcionou participar mais ativamente do cotidiano organizacional e a pensar na qualificação de suas competências.

Dessa maneira, inseridos na dinâmica contemporânea das organizações, os profissionais de secretariado assumem perfil diferenciado, mais proativo, multifuncional e empreendedor, voltado, além da assessoria, também à gestão (Boeira \& Durante, 2010; Moreira et al., 2016). A Figura 2 apresenta as mudanças na atuação secretarial associadas às competências desenvolvidas durante a formação. Estas que contribuíram para a mudança de um status de atuação operacional para outro mais estratégico.

\section{Figura 2}

Transformação na atuação secretarial

\begin{tabular}{|c|c|c|}
\hline Antes & Depois & Competências \\
\hline Executora de tarefas & Gerenciamento & $\begin{array}{l}\text { Exercício de funções gerenciais, com sólido domínio } \\
\text { sobre planejamento, organização, controle e } \\
\text { direção. }\end{array}$ \\
\hline Datilógrafa & Redação e Editoração de textos & $\begin{array}{l}\text { Adoção de meios alternativos relacionados com } \\
\text { a melhoria da qualidade e da produtividade } \\
\text { dos serviços, identificando necessidades e } \\
\text { equacionando soluções. }\end{array}$ \\
\hline Arquivista & $\begin{array}{l}\text { Planejadora, organizadora e } \\
\text { mantenedora de dados e } \\
\text { informações em arquivos, } \\
\text { inclusive eletrônicos }\end{array}$ & $\begin{array}{l}\text { Gerenciamento de informações, assegurando } \\
\text { uniformidade e referencial para diferentes } \\
\text { usuários. } \\
\text { Capacidade de maximização e otimização dos recursos } \\
\text { tecnológicos. }\end{array}$ \\
\hline Atendente de telefone & Atendimento global aos clientes & $\begin{array}{l}\text { Gestão e assessoria administrativa com base em } \\
\text { objetivos e metas departamentais e empresariais. }\end{array}$ \\
\hline “Quebra-galhos" & $\begin{array}{l}\text { Intermediadora de acontecimentos, } \\
\text { negociadora, facilitadora }\end{array}$ & $\begin{array}{l}\text { Visão generalista da organização e das peculiares } \\
\text { relações hierárquicas e intersetoriais. }\end{array}$ \\
\hline Atividades Mecânicas & Uso da criatividade & $\begin{array}{l}\text { Iniciativa, criatividade, determinação, vontade de } \\
\text { aprender, abertura às mudanças, consciência das } \\
\text { implicações e responsabilidades éticas do seu } \\
\text { exercício profissional. }\end{array}$ \\
\hline Ações em submissão & Ações empreendedoras & $\begin{array}{l}\text { Habilidade de lidar com modelos inovadores de } \\
\text { gestão. }\end{array}$ \\
\hline
\end{tabular}




\begin{tabular}{|c|c|c|}
\hline Antes & Depois & Competências \\
\hline Dependente & Autônoma & $\begin{array}{l}\text { Capacidade de articulação de acordo com os níveis de } \\
\text { competências fixadas pelas organizações. }\end{array}$ \\
\hline Disponível & Acessível & $\begin{array}{l}\text { Utilização do raciocínio lógico, crítico e analítico, } \\
\text { operando com valores e estabelecendo relações } \\
\text { formais e causais entre fenômenos e situações } \\
\text { organizacionais. }\end{array}$ \\
\hline Seguidora & Líder & $\begin{array}{l}\text { Receptividade e liderança para o trabalho em equipe, } \\
\text { na busca da sinergia. }\end{array}$ \\
\hline Resolvedora de problemas & Realizadora de previsões objetivas & $\begin{array}{l}\text { Domínio dos recursos de expressão e de comunicação } \\
\text { compatíveis com o exercício profissional, inclusive } \\
\text { nos processos de negociação e nas comunicações } \\
\text { interpessoais ou intergrupais. }\end{array}$ \\
\hline Cartão de visitas & $\begin{array}{l}\text { Agente de marketing e } \\
\text { endomarketing }\end{array}$ & $\begin{array}{l}\text { Eficaz utilização de técnicas secretariais, com } \\
\text { renovadas tecnologias, imprimindo segurança, } \\
\text { credibilidade e fidelidade no fluxo de } \\
\text { informações. }\end{array}$ \\
\hline
\end{tabular}

Nota. Natalense (1995) e Brasil (2005).

Constata-se, por meio da Figura 2, que houve significativas transformações em termos de atuação profissional, as quais acompanham aquilo anteriormente discutindo em termos de historicidade. Diante disso, a evolução das competências secretariais, as quais são construídas no sentido de proporcionar ao sujeito secretário posicionamento mais estratégico (Rodrigues, Lavarda, \& Martins, 2017) e menos operacional, constituem um arcabouço de evolução em termos de teoria e ação no contexto do secretariado. Acrescenta-se ao verificado, as palavras de Marinho (2014), quando expõe que a mudança no perfil do profissional indica que ele passou a atuar como um agente ativo e cooperativo nas organizações.

No Brasil, foi na década de 1950, com a chegada das multinacionais do segmento automobilístico, que a entrada do profissional de secretariado no mercado de trabalho se intensificou (Ribeiro, 2002). Porém, a profissão perdeu seu caráter informal no país apenas no ano de 1985, com a Lei n.o 7.377, de 30 de setembro de 1985 (Brasil, 1985).

Ainda sobre o contexto brasileiro, Nonato Júnior (2009) ressalta que a atualização do Secretariado na Classificação Brasileira de Ocupações (CBO) do Ministério do Trabalho e Emprego (MTE) foi uma grande conquista, no ano de 2002. Na referida Classificação, o secretário executivo faz parte do segundo grande grupo, o GG2, chamado Profissionais das Ciências e das Artes, que "compreende as ocupações cujas atividades principais requerem para seu desempenho conhecimentos profissionais de alto nível e experiência em matéria de ciências físicas, biológicas, sociais e humanas" (Ministério do Trabalho e Emprego, 2017). As atividades desse grande grupo "consistem em ampliar o acervo de conhecimentos científicos e intelectuais, por meio de pesquisas; aplicar 
conceitos e teorias para solução de problemas ou por meio de educação, assegurando a difusão sistemática desses conhecimentos" (Ministério do Trabalho e Emprego, 2017).

Observa-se, no entanto, que para alcançar esse perfil é necessária formação específica, diante da premência de aprofundamento do conhecimento, de habilidades e de atitudes perante as responsabilidades designadas ao profissional de secretariado em tempos atuais. Assim, no que se refere à formação, destaca-se a Resolução n. 0 3, de 23 de junho de 2005, que institui as Diretrizes Curriculares Nacionais (DCNs) para o curso de graduação em secretariado executivo (Brasil, 2005). No documento estão dispostos, dentre outros, o perfil e as competências que a formação deve possibilitar ao acadêmico, visto que, quando findado o curso superior, devem estar capacitados e aptos para "compreender as questões que envolvam sólidos domínios científicos, acadêmicos, tecnológicos e estratégicos, específicos de seu campo de atuação, assegurando eficaz desempenho de múltiplas funções de acordo com as especificidades de cada organização [...]" (Brasil, 2005, p. 79). Destaca-se, ainda, que as DCNs, em seu artigo 4ำ, apresentam um rol de competências a serem desenvolvidas durante a formação, as quais estão expressas no Figura 2, associadas à evolução da profissão secretarial.

Sobre tais exigências, Willers e Bortolotto (2005), Leal e Dalmau (2014) e Moreira et al. (2016) manifestam que a incorporação de competências diferenciadas no perfil secretarial, permitiu ao profissional ocupar lugar junto aos dirigentes nas organizações e assumir equipes de trabalho. Tornaram-se, ainda, segundo os autores, profissionais capacitados para identificar problemas, propor soluções, intervir e analisar dados e informações. Camargo, Nascimento, Bührer, Martinelli e Bahls (2015, p. 11) acrescentam que "esse profissional se mostra capaz de comandar e auxiliar o trabalho de variados departamentos, dessa forma, passa a exercer o papel de coordenador e assessor".

Ao retomar a questão da atuação secretarial em um cenário de constantes transformações, lembra-se que Sabino e Marchelli (2009, p. 606) chamam atenção para as críticas em relação a não associação entre a prática secretarial alinhada ao conhecimento:

No âmbito meramente prático, de pouco ou mesmo nada em termos de teorias e reflexões científicas os secretários precisam dispor para realizar seu trabalho. Nesse caso, a eles se imputa meramente saber operar instrumentos ou pensar segundo conceitos acabados, sem nunca explorar a possibilidade de aperfeiçoar seu conhecimento a respeito do contexto organizacional, para atuar com base em princípios teóricos passíveis de cientificidade.

Os autores afirmam que, para o secretário atuar, é preciso que haja fundamentação teórica associada à prática cotidiana e, nesse sentido, Wamser (2010) lembra que para ter condições de atuar com excelência, o secretário executivo deve privilegiar a busca de competências na área de gestão. Nessa perspectiva, Marinho (2014, p. 26) evidencia o perfil díspar que o profissional apresenta, de modo que é comum "questionar processos de trabalho, formas de negociação, buscar melhorias em técnicas já existentes ou ainda desenvolver e auxiliar novas estruturas de poder e liderança dentro das organizações". 
Diante do apresentado é fato que a profissão secretarial evoluiu ao longo do tempo, distanciando-se dos pressupostos do modelo de gestão puramente funcionalista (Souza, 2017). A mudança basilar no perfil do secretário executivo está na transição do campo puramente operacional para o campo gerencial/estratégico, no qual o profissional assume uma posição mais ativa em oposição à atuação passiva do passado (Rodighero \& Grzybovski, 2009).

Todavia, é importante lembrar que o secretário não deixou de executar as tarefas que executava anteriormente, tais como atender ao telefone, redigir e encaminhar correspondências, arquivar documentos, dentre outras. Porém, a atuação secretarial não deve ser considerada apenas como prática profissional isoladamente, "mas também como práxis que incorpora conceitos teóricos, consciência reflexiva e domínio de teorias científicas" (Sabino \& Marchelli, 2009).

Portanto, dispondo dos conhecimentos específicos que levem à compreensão da complexidade teórica do seu trabalho prático, o secretário-executivo compreenderá o entorno conceitual, em que suas atribuições se desenvolvem (Sabino \& Marchelli, 2009). Como afirma Durante (2010, p. 17), "não se trata de excluir da profissão as técnicas e procedimentos, mas de agregar uma atitude diferenciada diante de tais técnicas, como a atitude de reflexão sobre o fazer e de interferência nessa realidade, e não de alienação e submissão". Assim, findadas as considerações teóricas deste estudo, apresentam-se, na sequência, os caminhos metodológicos aplicados para o desenvolvimento desta pesquisa.

\section{Procedimentos Metodológicos}

Observado que houve evolução no campo secretarial, em termos de posicionamento na estrutura organizacional, ou seja, de que o profissional de secretariado passou da atuação em nível operacional para o estratégico e, além disso, que tal fato está alinhado a uma questão epistemológica pouco explorada na área, este estudo busca, por meio da dicotomia objetividade-subjetividade, identificar elementos que caracterizam esse fenômeno, principalmente, após a era tecnológica, momento em que o secretariado sofre relevante mudança em termos de atuação.

A partir de tais aspectos, esta pesquisa se configura como de natureza básica, visto que o intuito é a concentração de conhecimentos e informações para sustentação de resultados acadêmicos ou outros de importância específica (Schwartzman, 1979). Nesse sentido, pretende-se contribuir com informações e reflexões para as pesquisas na área secretarial.

Quanto aos objetivos, trata-se de uma investigação descritiva que, conforme Vergara (2007), é aquela que descreve as características de um determinado fenômeno e/ou a relação entre as variáveis que o compõem. Assim, neste estudo são descritas as relações entre a dicotomia proposta e a ocorrência dela no campo secretarial.

Em termos de abordagem, adotou-se a qualitativa, que tem como fundamento o estudo e a análise do mundo empírico, por meio de dados descritivos sobre pessoas, lugares ou processos interativos, a fim de compreender o fenômeno, a partir daquilo que vivencia o sujeito participante (Godoy, 1995). Sob essa perspectiva, esta investigação se preocupou em analisar, no sentido epistemológico, um processo evolutivo da profissão 
secretarial no contexto brasileiro, a partir das competências técnicas e comportamentais presentes na atuação do profissional de secretariado.

Por se tratar de uma pesquisa bibliográfica, os dados foram coletados em material já consolidado sobre os temas abordados, cujas fontes foram livros e artigos científicos. E, ainda, contou-se com a pesquisa documental, relacionada aos regramentos jurídicos que normatizam a atuação secretarial (Vergara, 2007). Observa-se que, a partir do escopo teórico apresentado neste estudo, foram criadas categorias analíticas que permitiram uma análise constitutiva e operacional daquilo ora proposto. Em outras palavras, possibilitaram uma investigação ancorada em conceitos teóricos alinhados a evolução empírica, relacionada ao profissional de secretariado. Tais categorias analíticas estão descritas na Figura 3.

\section{Figura 3}

Estrutura teórico-analítica.

\begin{tabular}{|c|c|c|c|c|}
\hline $\begin{array}{c}\text { Dimensão teórico- } \\
\text { analítica }\end{array}$ & $\begin{array}{l}\text { Objetivo } \\
\text { de estudo }\end{array}$ & Atores sociais & $\begin{array}{l}\text { Categoria Analítica } \\
\qquad \text { (CA) }\end{array}$ & Proposição teórica \\
\hline - A Dicotomia & Discutir como se & Praticantes: aqueles & Práticas: & A complementaridade \\
\hline Objetividade & estabelece a & que realizam & as ferramentas sociais, & se estabelece \\
\hline \multirow[t]{2}{*}{ /Subjetividade } & complementaridade & as atividades, & simbólicas e & na dicotomia \\
\hline & na dicotomia & a partir das & materiais por & Objetividade/ \\
\hline - A Práxis no campo & objetividade & práticas, por meio & meio das quais & Subjeti-vidade \\
\hline \multirow[t]{8}{*}{ secretarial } & subjetividade, & de processos & as atividades & por meio das \\
\hline & relacionada ao & interativos que & ocorrem, que & práticas que os \\
\hline & processo de & promovem & se desdobram & praticantes do \\
\hline & construção da & ação coletiva & em ações & campo secretarial \\
\hline & práxis no campo & (Jarzabkowski & (Jarzabkowski, & realizam em prol \\
\hline & secretarial & et al., 2007; & 2005; & da construção \\
\hline & & Whittington, & Whittington, & da práxis desse \\
\hline & & 2006) & 2006) & campo. \\
\hline
\end{tabular}

Nota. Elaborado pelas autoras (2019).

Definidas as categorias analíticas, optou-se como método para interpretação dos dados, a Análise de Conteúdo. De acordo com Bardin (2011), a referida técnica trata de explicitar e sistematizar o conteúdo de mensagens ou expressões, embasados em índices passíveis ou não de quantificação, a partir de um conjunto de técnicas e, nesse sentido, o analista tem a sua disposição ou cria operações analíticas, adaptáveis à natureza daquilo que se procura resolver.

\section{Análise e Discussão}

É importante lembrar que a dicotomia analisada está ancorada na evolução das atividades secretariais que, em tempos passados, eram ajustadas para o campo puramente operacional e, hoje, adequam-se à atuação em áreas mais estratégicas. Nesse sentido, entende-se que as ações secretariais operacionais estão alinhadas à 
objetividade, cuja presença de padrões impede a vontade do sujeito, sem preferências ou vieses Bruce e Yearley (2006). Em outras palavras, é submeter-se às regulações daquilo que está determinado tanto no que se refere à organização em si, quanto em relação à sociedade.

Todavia, quando o secretário passa a atuar como gestor, acredita-se que há tendências para o subjetivismo, ou seja, o olhar menos determinista daquilo que é somente "praticar" o que já está modelado, passa a voluntarista e, sob essa perspectiva, há o envolvimento do indivíduo gestor não só com a realização da tarefa, mas também, com aquele que a executa. Em outras palavras, a percepção da realidade envolve as percepções ou representações do sujeito (Abbagnano, 2007). Na Figura 4, apresenta-se uma síntese do ora discutido.

Figura 4

Síntese: objetividade-subjetividade na atuação secretarial

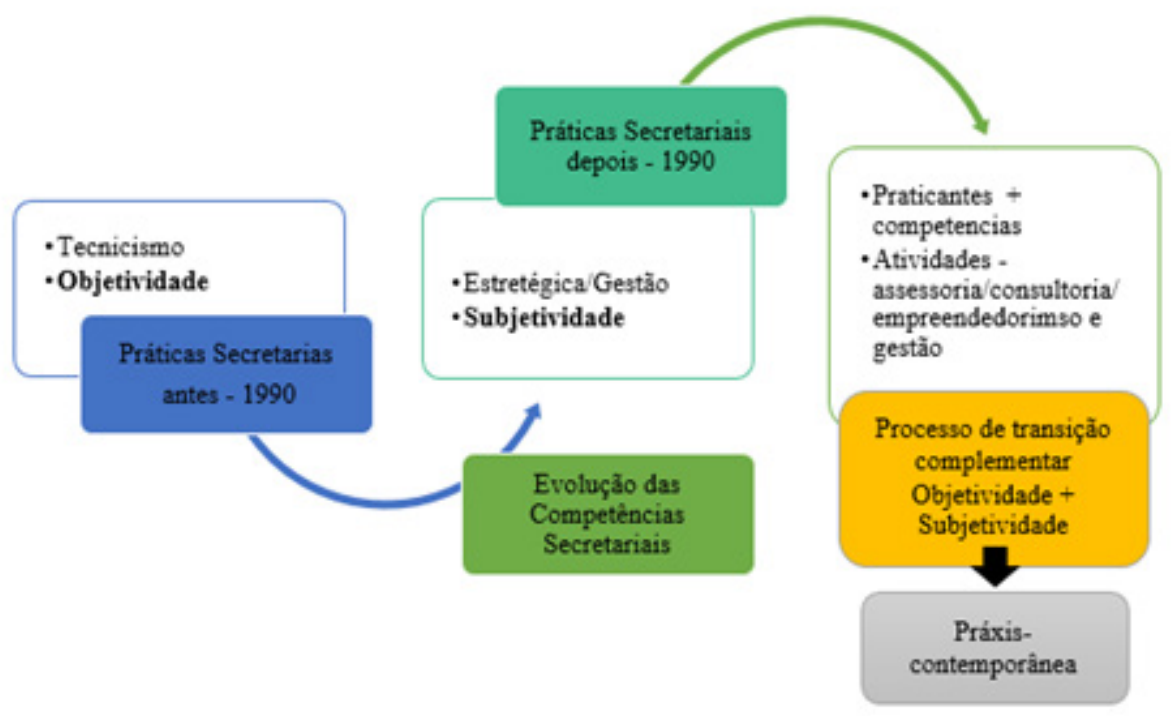

Nota. Elaboração própria (2019).

A análise da Figura 1 permite compreender que, no contexto tecnicista, as práticas secretarias materializavam-se na atuação desprovida da necessidade de competência mais robustas. A exigência era apenas a de executar tarefas (Natalense, 1995). Nesse sentido, supõe-se que, em termos de conhecimento e habilidades, as ações eram restritas àquilo que a chefia determinava e, em relação à atitude, a passividade era predominante, conforme comentado por (Rodighero e Grzybovski (2009). Essa conjuntura alinha-se a teoria de Bourdieu (1990), quando explica que o sujeito age independentemente daquilo que pensa ou deseja, visto que a estrutura objetiva condiciona e orienta suas ações, práticas e representações. É, também, uma característica da objetividade, visto a concepção de que se trata da ocorrência de ações independentemente daquilo que é voluntarioso do sujeito (Abbagnano, 2007; Bruce \& Yearley, 2006; Japiassú \& Marcondes, 2001).

Julga-se que, a partir do reconhecimento da profissão (Leis), da regulação dos cursos de graduação (Diretrizes Curriculares) e das mudanças no campo mercadológico (que passou a exigir profissionais distintos), que a profissão secretarial, assumiu status diferenciado e passou a figurar em nível gerencial. A transição de executor para a de gestor da rotina organizacional, possibilita ao secretário ações mais estratégicas, para as quais, a compreensão do ambiente é macro e, sendo assim, o simples fazer não mais se encaixa. Sob tal aspecto, tem-se 
que o perfil profissiográfico contemporâneo do secretário o permite assumir uma posição mais ativa em área mais estratégica (Moreira et al., 2016; Rodighero \& Grzybovski, 2009; Rodrigues et al., 2017).

Complementam a reflexão, Souza, Juliatto, Moreira e Vale (2017), quando consideram que é fato que a profissão secretarial evoluiu ao longo do tempo, distanciando-se dos pressupostos do modelo de gestão puramente funcionalista. Ou seja, o secretário, a partir de uma formação multidisciplinar, desenvolve-se para a atuação proativa, polivalente, com uma visão holística sobre o negócio como um todo e, ainda, sobre si mesmo e o outro; além de sua contribuição para a sociedade, assume uma postura mais interpretativista no contexto organizacional e social. Vale destacar, que as transformações paradigmáticas permitiram, ainda, que o gênero masculino retornasse ao campo secretarial, quebrando a hegemonia feminina que dominava o cenário desde o início do Século XX.

Melhor dizendo, os praticantes, em um movimento de evolução paradigmática do contexto em que atuavam, buscaram a transformação da prática vivenciada, concordando com Bourdieu (1996), quando explica que é na prática que o habitus do sujeito se atualiza. Assim, o profissional secretário, transforma a prática tecnicista em estratégica, alicerçado pelo desenvolvimento de competências direcionadas para a atuação gerencial. Nessa direção, as percepções (subjetividade) do sujeito secretário acerca da mudança contextual do ambiente organizacional o conduziram a transmutações práticas, que fomentadas pela reflexão crítico analítica reconstruíram a práxis de atuação.

Outra compreensão possível é a de que os praticantes, mesmo que inteiramente obedientes às estruturas (tecnicistas), se mostraram em algum momento conscientes delas e buscaram desenvolver uma relativa autonomia, pois, como alerta Schenato (2011) não é possível mudar sem considerar os condicionamentos sob os quais o sujeito se posiciona. Em outras palavras, o secretário atuando em um ambiente que passava por modificações (era tecnológica) compreendeu que as práticas, poderiam ser sustentadas pela reflexão crítica/teórica, estabelecendo assim um processo de construção de uma práxis (Sabino \& Marchelli, 2009) sustentada pela dicotomia objetividade (prática) - subjetividade (reflexão).

Considerada a concepção, reconhece-se uma sucessão com bases construtivistas na qual o praticante, a partir de uma determinada realidade, busca conhecê-la, interpretá-la e recriá-la (Grisales, 2011) e, nesse processo insere-se a si próprio, recriando a si mesmo. Isto é, o secretário a partir de uma realidade extremamente objetiva, busca transformá-la e, em meio a isso, transmuta sua própria forma de atuação. A objetividade, neste caso, é considerada o ponto de partida da subjetividade, associando-se a concepções prévias do indivíduo (Costa \& Krüger, 2003).

É importante dizer que esta reflexão não exclui os procedimentos técnicos que envolvem a atuação secretarial, mesmo por que, da prática da gestão, infere-se ações técnicas. O que é necessário ficar evidente é a mudança na postura da atuação, na qual a objetividade encontra espaço como elemento estruturante de ações sustentadas pela racionalidade e não pela alienação. Em outras palavras, na qual o praticante constrói uma práxis a partir de dois elementos complementares: a objetividade daquilo que é necessário realizar, somado a subjetividade que Ihe permite analisar a conjuntura a partir de suas percepções sobre o contexto. 


\section{Considerações Finais}

Considerada a concepção de que o pesquisador trabalha com e para desenvolver o conhecimento de natureza científica, e que, para tanto, é preciso sair da "caixa" e explorar temas que contribuem para a evolução de um campo científico, este estudo buscou experimentar outros caminhos para se investigar um tema tratado de forma mais técnica na área secretarial. Em outras palavras, buscou-se aprofundar uma transformação evidente na atuação do profissional de secretariado, mas que, no entanto, não havia sido verificada sob a ótica do debate epistemológico.

Assim, este estudo teve como objetivo discutir como se estabelece a complementaridade na dicotomia objetividade-subjetividade, relacionada ao processo de construção da práxis no campo secretarial. Assim definido, identificou-se aspectos inerentes à dicotomia ora discutida, na transição de postura do sujeito secretário, que antes se caracterizava por realizar ações como um agente passivo e executor de tarefas, para um perfil contemporâneo, cuja tônica é a proatividade e o posicionamento de gestor que o profissional alcançou.

Vale dizer que, alcançado o objetivo deste estudo, identificou-se, como limitação, os poucos estudos na área secretarial no campo epistemológico. Nesse sentido, para estudos futuros propõe-se a ampliação de pesquisas na área, inclusive desta, que faz parte de um projeto, que visa o aprofundamento, em termos científicos, do secretariado. Todavia, observa-se nos últimos anos, acerca do campo secretarial, o comprometimento cada vez maior dos pesquisadores da área em fomentar a atuação técnica alinhada com a cientificidade. Entende-se, com isso, que se promove e impulsiona transformações relevantes na profissão. Sob tal circunstância, é possível dizer que a pesquisa é essencial para o secretariado, mesmo que a ideia de uma profissão voltada apenas para o mercado de trabalho seja a perspectiva de muitos que a buscam. 


\section{Referências}

Abbagnano, N. (2007). Dicionário de filosofia (5th ed.). São Paulo. Martins Fontes.

Adelino, F. J., \& Silva, M. A. V. (2012). A Tecnologia da Informação como Agente de Mudança no Perfil do Profissional de Secretariado. Revista de Gestão e Secretariado, 3(2), 5-23.

Barbosa da Silva, A., \& Neto, R. J. (2006). Perspectiva multiparadigmática nos estudos organizacionais. In A. (Orgs. Kleinübing, C; Brandeira-de-Mello, R; Barbosa da Silva (Ed.), Pesquisa qualitativa em estudos organizacionais: paradigmas, estratégias e métodos (pp. 53-87). Saraiva.

Bardin, L. (2011). Análise de conteúdo. Coimbra. Edições 70.

Boeira, D. A. R., \& Durante, D. G. (2010). Gestão Secretarial: O papel do secretário executivo na gestão do conhecimento organizacional. Passo Fundo. Universidade de Passo Fundo.

Bourdieu, P. (1990). Coisas ditas. São Paulo. Brasiliense.

Bourdieu, P. (1996). Espaço social e espaço simbólico. In Razões práticas: sobre a teoria da ação (pp. 13-33). Campinas. Papirus.

Bourdieu, P. (2001). Meditações pascalianas. Rio de Janeiro. Bertrand Brasil.

Brasil. (1985). Lei n. ${ }^{\circ}$ 7.377, de 30 de setembro de 1985. Dispõe sobre o exercício da profissão de secretário, e dá outras providências. Diário Oficial [da] República Federativa do Brasil.

Brasil. (2005). Ministério da Educação. Resolução nº 3, de 23 de junho de 2005. Institui as Diretrizes Curriculares Nacionais para o curso de graduação em Secretariado Executivo e dá outras providências. http://portal.mec. gov.br/cne/arquivos/pdf/rces003 05.pdf

Bruce, S., \& Yearley, S. (2006). The sage dictionary of sociology. New York. Sage Publications.

Burrel, G., \& Morgan, G. (1979). Sociological Paradigms and Organizational Analysis (traduzido) (W. Martins (ed.)). Portsmouth. Heinemann Educational Books.

Camargo, M., Nascimento, L., Bührer, V., Martinelli, G., \& Bahls, T. (2015). A evolução da área secretarial às ciências da assessoria. Revista Expectativa, XIV (14), 1-23. https://doi.org/10.48075/revex.v14i1.9355

Costa, R., \& Krüger, V. (2003). Concepções sobre objetividade/subjetividade no fazer ciência e possíveis implicações na sala de aula universitária. IV Encontro Nacional de Pesquisa Em Educação Em Ciências, 1-11. http://fep. if.usp.br/ profis/arquivos/ivenpec/Arquivos/Orais/ORAL054.pdf

Durante, D. G. (2010). Tópicos especiais em técnicas de secretariado. Curitiba. IESDE Brasil S. A.

Giddens, A. (1984). A constituição da sociedade. Martins Fontes.

Godoy, A. S. (1995). Introdução à pesquisa qualitativa e suas possibilidades. Revista de Administração de Empresas, 35(2), 57-63.

Grisales, R. M. (2011). El debate positivism-constructivismo en Francia: una mirada desde las ciências de la gestión. In Formar en administración: por una nueva fundamentación filosófica. Siglo Del Hombre.

Hatchuel, A. (2005). Towards in Epistemology of colletive action: Management research as a responsive and actionable discipline. European Management Review, 2, 36-47. 
Japiassu, H. (1991). Introdução ao pensamento epistemológico. Rio de Janeiro. Francisco Alves.

Japiassú, H., \& Marcondes, D. (2001). Dicionário básico de filosofia (3rd ed.). Rio de Janeiro. Jorge Zahar Editor. Jarzabkowski, P. (2005). Strategy as practice. New York. Sage Publications.

Jarzabkowski, P., Balogun, J., \& Seidl, D. (2007). Strategizing: The challenges of a practice perspective. 60(1), 5-27. https://doi.org/10.1177/0018726707075703

Lane, S. T. M. (2002). A dialética da subjetividade versus objetividade. In F. L. G. (orgs) Furtado, O; Rey (Ed.), Por uma epistemologia da subjetividade: Um debate entre a teoria sócio-histórica e a teoria das representações sociais. São Paulo. Casa do Psicólogo.

Le Moigne, J.-L. (2007). Chapitre IV: Les hypotheses fondatrices des épistémologies constructivistes. In Les épistémologies constructivistes (3rd ed.). Paris. PUF.

Leal, F. G., Baptista, \& Dalmau, M. B. (2014). Formação e perspectivas de atuação do secretário executivo no Brasil Competência : um conceito em construção. 71-85.

Maçaneiro, M. B., \& Kuhl, M. R. (2013). Estado da Arte e o Rumo do Conhecimento Científico em Secretariado Executivo: Mapeamento e Análise de Áreas de Pesquisa. Revista de Gestão e Secretariado, 04(03), 157-188. https://doi.org/10.7769/gesec.v4i3.274

Marinho, J. N. (2014). Competências especiais para o desenvolvimento contínuo do profissional de secretariado executivo. São Paulo. SinSesp.

Martins, C. B., Leal, F. G., Souza, E. C. P., \& Todorov, M. do C. A. (2017). A Busca da Cientificidade do Secretariado no Contexto Brasileiro: Aspectos Históricos e Contemporâneos. Revista Gestão Em Análise, 6(1/2), 270. https:// doi.org/10.12662/2359-618xregea.v6i1/2.p270-286.2017

Ministério do Trabalho e Emprego. (2017). Classificação brasileira de ocupações - CBO. http://www.mtecbo.gov.br/ cbosite/pages/home.jsf

Moreira, K. D. (2018). Proposição metodológica para o desenvolvimento de competências secretariais no contexto da gestão universitária. Universidade Federal de Santa Catarina, Centro Socioeconômico, Programa de PósGraduação em Administração.

Moreira, K. D., Rodrigues, L. M. A., Vale, J. C. F. do, \& Rosa, M. H. (2016). As competências contemporâneas do secretário executivo e a relação com as competências do Middle Manager. Revista de Gestão e Secretariado - GeSeC, 7(1), 45-66. https://doi.org/10.7769/gesec.7i1.400

Mozzato, A. R., \& Grzybovski, D. (2014). Abordagem crítica nos estudos organizacionais: concepção de indivíduo sob a perspectiva emancipatória. Cadernos EBAPE.BR, 11(4), 503-519. https://doi.org/10.1590/s1679$\underline{39512013000400003}$

Natalense, M. L. C. (1995). Secretária executiva: manual prático. São Paulo. IBO.

Neiva, E. G., \& D’Elia, M. E. S. (2009). As novas competências do profissional de secretariado. IOB.

Nonato Junior, R. (2009). Epistemologia e teoria do conhecimento em Secretariado Executivo: A fundação das ciências da assessoria. Fortaleza. Expressão Gráfica. 
Orlikowski, W. J. (2010). Engaging practice in research: phenomenon, perspective, and philosophy. In D. Golsorkhi \& (Ed.) (Eds.), The Cambridge handbook on strategy as practice (pp. 23-33). Cambridge. Cambridge University Press.

Peci, A. (2006). Além da dicotomia objetividade-subjetividade. In D. Vieira, M. M. F.; Zouain (Ed.), Pesquisa Qualitativa em Administração. São Paulo. Editora FGV.

Ribeiro, N. de L. A. (2002). Secretariado: do escriba ao gestor: Um estudo sobre o novo perfil do profissional de secretariado. Curitiba. Fama.

Rodighero, D., \& Grzybovski, D. (2009). Gestão do conhecimento e o profissional de secretário executivo. In A. A. (Orgs. Durante, D. G.; Fávero (Ed.), Gestão secretarial: formação e atuação profissional. Passo Fundo. Universidade de Passo Fundo.

Rodrigues, L. M. A., Lavarda, R. A. B., \& Martins, C. B. (2017). O profissional de secretariado executivo: gestor de informações no processo de formação da estratégia. Capital Científico, 15(3), 112-128.

Sabino, R. F., \& Marchelli, P. S. (2009). O debate teórico-metodológico no campo do secretariado: pluralismos e singularidades. Cadernos EBAPE.BR, 7(4), 607-621. https://doi.org/10.1590/S1679-39512009000400006

Schenato, V. C. (2011). A síntese entre objetividade e subjetividade mediada pela noção de habitus em Bourdieu. Perspectivas Sociais, 1(1), 31-46.

Schwartzman, S. (1979). Pesquisa acadêmica, pesquisa básica e pesquisa aplicada em duas comunidades científicas. http://www.schwartzman.org.br/simon/acad ap.htm

Serva, M., Dias, T., \& Alperstedt, G. D. (2010). Paradigma da complexidade e teoria das organizações: uma reflexão epistemológica. Revista de Administração de Empresas, 50(3), 276-287. https://doi.org/10.1590/S0034-

\section{$\underline{75902010000300004}$}

Souza, Stefani de. (2017). O quadro de pessoal do cargo de secretário-executivo da Universidade Federal de Santa Catarina. https://repositorio.ufsc.br/bitstream/handle/123456789/186602/PPAU0156-D.pdf?sequence=1\&isAllowed $=\mathrm{y}$

Souza, S. de, Juliatto, D. L., Moreira, K. D., \& Vale, J. C. F. do (2017). Concepções teóricas sobre a atuação secretarial associada à gestão do conhecimento. I/ Encontro de Estudos e Pesquisas Em Secretariado Executivo - /I ENEPES.

Veiga, D. R. (2010). Guia de secretariado: técnicas e comportamento. São Paulo. Érica.

Vergara, S. C. (2007). Projetos e relatórios de pesquisa em administração. São Paulo. Atlas S.A.

Wamser, E. (2010). A secretária que faz: vivências e convivências. Blumenau. Nova Letra.

Whittington, R. (2006). Completing the practice turn in strategy research. Organization Studies, 27(5), 613-634. https://doi.org/10.1177/0170840606064101

Willers, E. M., \& Bortolotto, M. F. P. (2005). Profissional de secretariado executivo: explanação das principais características que compõem o perfil. Revista Expectativa, 4(4), 45-56. 